\title{
Inventarisasi Jamur Tingkat Tinggi (Basidiomycetes) Di Taman Wisata Alam Muka Kuning Batam
}

\section{Inventory Of Macrofungi (Basidiomycetes) At Taman Wisata Alam Muka Kuning Batam}

\author{
Liska Chairani Harahap $^{1 *}$, Fauziah Syamsi², Yarsi Efendi ${ }^{3}$ \\ ${ }^{123}$ Program Studi Pendidikan Biologi Universitas Riau Kepulauan \\ *Korespondensi: liskachairani@gmail.com
}

\begin{abstract}
Abstrak
Penelitian ini bertujuan untuk mengetahui jenis jamur tingkat tinggi (Basidiomycetes) yang ada di Taman Wisata Alam Muka Kuning Batam dan data yang diperoleh dikembangkan menjadi media pembelajaran yaitu media poster. Metode yang digunakan adalah survei di sepanjang jalur hutan di TWA Muka Kuning Batam. Jenis penelitian ini adalah penelitian deskriptif eksploratif. Berdasarkan hasil analisis diperoleh data jenis jamur tingkat tinggi (Basidiomycetes) di Taman Wisata Alam Muka Kuning Batam terdapat 7 famili yaitu Ganodermataceae, Hygrophoraceae, Hymenochaetaceae, Polyporaceae, Schizophyllaceae, Steccherinaceae dan Tricholomataceae. Dan 15 jenis jamur tingkat tinggi (Basidiomycetes) yaitu Amauroderma rugosum, Ganoderma applanatum, Ganoderma sp., Hygrocybe sp., Hymenochaete sp., Fomes sp., Microporus xanthopus, Panus sp., Polyporus sp., Pycnoporus sanguineus, Trametes sp., Schizophyllum commune., Nigroporus vinosus, Marasmius androsaceus dan Marasmius sp.
\end{abstract}

Kata kunci : Jamur Tingkat Tinggi (Basidiomycetes), Identifikasi, Media Pembelajaran.

\begin{abstract}
This study aims to determine the type Macrofungi (Basidiomycetes) in the Taman Wisata Alam Muka Kuning Batam and the data obtained developed into a medium of learning that is the media poster. The method used is a survey along the forest path at TWA Muka Kuning Batam. The type of this research is descriptive explorative research. Based on the analysis results obtained data of Macrofungi (Basidiomycetes) in Taman Wisata Alam Muka Kuning Batam there are 7 families namely Ganodermataceae, Hygrophoraceae, Hymenochaetaceae, Polyporaceae, Schizophyllaceae, Steccherinaceae and Tricholomataceae. And 15 types of Macrofungi (Basidiomycetes) are Amauroderma rugosum, Ganoderma applanatum, Ganoderma sp., Hygrocybe sp., Hymenochaete sp., Fomes sp., Microporus xanthopus, Panus sp., Polyporus sp., Pycnoporus sanguineus, Trametes sp., Schizophyllum commune, Nigroporus vinosus, Marasmius androsaceus and Marasmius sp.
\end{abstract}

Keywords: Macrofungi (Basidiomycetes), Identification, Learning Media.

\section{PENDAHULUAN}

Jamur merupakan organisme yang tidak berklorofil, sehingga tidak dapat menyediakan makanan sendiri dengan cara fotosintesis. Jamur memerlukan zat-zat makanan dengan menyerap dari proses pelapukan (Muchroji, 2004 dalamHasanuddin, 2014). Berdasarkan bentuk dan ukurannya jamur dapat dikelompokkan menjadi jamur mikroskopis dan jamur 


\section{SIMBIOSA Vol 6 (2): 74-84 Januari 2018}

Liska Chairani Harahap, Fauziah Syamsi, Yarsi Efendi: Inventarisasi Jamur Tingkat Tinggi ...

makroskopis. Jamur yang termasuk makroskopis adalah sebagian besar divisi Basidiomycota dan sebagian kecil Ascomycota (Dwidjoseputro, 1976 dalam Syafrizal dan Yeni, 2014).

Beberapa jenis jamur ada yang dimanfaatkan sebagai makanan, khasiat obat, dan lainlain serta ada juga jamur yang dapat mengakibatkan keracunan (Bahrun dam Muchroji, 2005 dalam Hasanudin, 2014). Selain itu dalam aspek ekologis jamur dapat mempengaruhi keseimbangan ekosistem, hal ini karena jamur merupakan pengurai utama yang menjaga ketersediaan nutrien anorganik yang sangat penting bagi pertumbuhan tumbuhan di ekosistem (Campbell, dkk., 2003).

Batam mempunyai luas hutan sebesar 52225,456 Ha (Badan Pusat Statistik Kota Batam, 2014). Satu diantara hutan yang terdapat di Batam adalah Hutan Wisata Pancur, Hutan ini mempunyai nama asli Taman Wisata Alam Muka Kuning. Kawasan Taman Wisata Alam Muka Kuning memiliki pohon-pohon yang tinggi dan udara yang lembab sehingga habitat yang sesuai untuk pertumbuhan jamur.

Beberapa penelitian terkait yang telah dilakukan diantaranya, di Sumatra Utara terdapat 5 jenis jamur tingkat tinggi dari genus Ganoderma. Di Hutan Pendidikan dan Pelatihan Tabo-Tabo Sulawesi Selatan terdapat 19 jenis jamur kayu (Suryanto, et al., 2005;Arif, et al., 2007 dalam Indra, 2014). Dalam hal ini belum ada dilakukan penelitian jenis jamur tingkat tinggi (Basidiomycetes) di Taman Wisata Alam Muka Kuning, Kota Batam. Oleh karena itu, perlu dilakukan penelitian untuk mengetahui jenis-jenis jamur tingkat tinggi (Basidiomycetes) yang ada di Taman Wisata Alam Muka Kuning Batam.

Hasil dari inventarisasi jamur tingkat tinggi ini merupakan informasi ilmiah yang dapat disajikan dan dikembangkan dalam bentuk media pembelajaran disekolah, sehingga dapat membantu guru dalam proses pembelajaran terutama pembelajaran pada materi jamur di kelas X SMA.

\section{METODE PENELITIAN}

Penelitian ini dilakukan pada bulan Maret-April 2017 di Taman Wisata Alam (TWA) Muka Kuning Batam. Alat yang digunakan yaitu keranjang, pisau, pensil dan buku catatan lapangan, tongkat kayu, kertas label, kamera, penggaris, kertas koran. Bahan yang digunakan yaitu Alkohol 70\%.

Pengambilan sampel di TWA Muka Kuning Batam dengan menggunakan metode survey di sepanjang jalur hutan. Sampel yang ditemukan difoto, dikoleksi dan dicatat bagian 
yang menjadi ciri pembeda dari jamur tersebut seperti: tudung, bilah, tangkai dan tempat tumbuh. Kemudian dilakukan identifikasi di Laboratorium Botani Universitas Riau Kepulauan Batam dengan menggunakan buku identifikasi jamur.

\section{HASIL DAN PEMBAHASAN}

Hutan Wisata Pancur atau Hutan Taman Wisata Alam Muka Kuning Batam merupakan salah satu kawasan konsevasi di Kota Batam yang mempunyai luas sekitar 2.065,62 Ha. yang diperuntukkan bagi perlindungan flora dan fauna. Hutan Taman Wisata Alam Muka Kuning Batam secara geografis terletak antara 1 ${ }^{\circ} 04^{\prime} 19,5$ 'N10400'47.3”E. Secara administrasi pemerintahan terletak di kawasan simpang dam, Muka Kuning, Kota Batam, Provinsi Kepulauan Riau, Indonesia.

Berdasarkan hasil penelitian di Taman Wisata Alam Muka Kuning Batam diperoleh beberapa jenis jamur yang tersaji dalam Tabel 1 dibawah ini.

Tabel 1. Jenis-jenis jamur tingkat tinggi yang terdapat di Taman Wisata Alam Muka Kuning Batam.

\begin{tabular}{|c|c|c|c|}
\hline No & Famili & Spesies & Tempat tumbuh \\
\hline \multirow[t]{3}{*}{1} & Ganodermataceae & 1. Amauroderma rugosum & Tanah \\
\hline & & 2. Ganoderma applanatum. & Kayu lapuk \\
\hline & & 3. Ganoderma sp. & Kayu lapuk \\
\hline 2 & Hygrophoraceae & 4. Hygrocybe sp. & Tanah \\
\hline 3 & Hymenochaetaceae & 5. Hymenochaete sp. & Kayu lapuk \\
\hline \multirow[t]{6}{*}{4} & Polyporaceae & 6. Fomes sp. & Kayu lapuk \\
\hline & & 7. Microporus xanthopus & Kayu lapuk \\
\hline & & 8. Panus sp. & Kayu lapuk \\
\hline & & 9. Polyporus sp. & Kayu lapuk \\
\hline & & 10. Pycnoporus sanguineus & Kayu lapuk \\
\hline & & 11. Trametes $s p$. & Kayu lapuk \\
\hline 5 & Schizophyllaceae & 12. Schizophyllum commune & Kayu lapuk \\
\hline 6 & Steccherinaceae & 13. Nigroporus vinosus & Kayu lapuk \\
\hline 7 & Tricholomataceae & $\begin{array}{l}\text { 14. Marasmius androsaceus } \\
\text { 15. Marasmius sp. }\end{array}$ & $\begin{array}{l}\text { Serasah daun } \\
\text { Kayu lapuk }\end{array}$ \\
\hline
\end{tabular}

Berdasarkan tabel di atas, dapat diketahui bahwa jenis jamur yang ditemukan di TWA Muka Kuning Batam adalah sebanyak 15 jenis jamur makroskopis. Jamur yang paling banyak ditemukan yaitu dari famili Polyporaceae dan dari semua jenis jamur yang ditemukan hanya 2 jenis jamur yang tempat hidupnya berada ditanah dan selebihnya hidup pada kayu lapuk. 


\section{SIMBIOSA Vol 6 (2): 74-84 Januari 2018}

Liska Chairani Harahap, Fauziah Syamsi, Yarsi Efendi: Inventarisasi Jamur Tingkat Tinggi ...

\section{Family Ganodermataceae}

Berdasarkan pengamatan di lapangan, ditemukan 3 jenis jamur yang termasuk dalam famili Ganodermataceae. Ganodermataceae merupakan Suatu keluarga jamur yang menghasilkan spora dengan struktur dinding yang kompleks, dinding spora dilapisi 2 lapis, dengan hiasan pada lapisan dalam menembus lapisan luar yang tidak berwarna. Badan buah bersifat tahunan atau abadi, mirip braket, dan berkayu atau teksturnya berkayu. Keluarga ini biasanya ditemukan di kayu, dan keluarga ini termasuk jamur kayu yang dapat membusuk (Encyclopedia, 2017).

Jamur Ganoderma disebut dengan jamur kayu karena hidup melekat pada kayu. Jamur ini juga biasanya dikenal dengan jamur Lingshi. Namun, sayangnya jamur ini tidak dapat dikonsumsi seperti jamur makro pada umumnya karena teksturnya yang keras namun dapat dimanfaatkan sebagai bahan campuran obat. Jamur Ganoderma dianggap mampu meningkatkan kekebalan tubuh manusia dari serangan penyakit, mampu menghambat pertumbuhan tumor, dan mampu meningkatkan stamina orang usia lanjut (Hassanudin, 2014).

Salah satu contoh jamur yang berkhasiat obat (medicinal mushroom) adalah Ganoderma lucidum. Jamur ini telah digunakan sebagai obat di kawasan Timur sejak berabad-abad yang lalu. Isolat-isolat yang digunakan dalam studi farmakologi dan kesehatan mencakup beberapa jenis Ganoderma sp. termasuk $G$. lucidum yang senyawa aktifnya berbeda sehingga disebut spesies kompleks. Kandungan senyawa yang terdapat pada ekstrak Ganoderma sp. diketahui memiliki khasiat sebagai antikanker (Chang dan Miles 1992; Hseu et al., 1996 dalam Sari, 2014).

\section{- Amauroderma rugosum}

Jamur ini mempunyai tudung berukuran $6 \mathrm{~cm}$, tubuh buah berbentuk setengah lingkaran, keras, berwarna coklat, memiliki tangkai, habitatnya di tanah dengan lingkungan yang lembab.

- Ganoderma applanatum

Jamur ganoderma mempunyai tubuh buah keras, berbentuk kipas, setengah lingkaran. Tidak memiliki tangkai. Permukaan atas berwarna kecoklatan. Permukaan bawah berwarna putih menjadi kotor kekuningan/ kuning kecoklatan. Tudung berukuran $6 \mathrm{~cm}$. Hidup sendiri atau bisa berkoloni pada kayu lapuk.

\section{- Ganoderma sp.}


Jamur ini memiliki tubuh buah berukuran kecil, berwarna coklat kekuningan pada bagian permukaan bawah berwarna putih dengan bentuk seperti setengah lingkaran. Tumbuh berkelompok pada batang kayu yang telah mati.Tidak ada cincin, tidak ada volva. Tudung berukuran $2,5 \mathrm{~cm}$. Habitatnya terdapat pada kayu lapuk.

\section{Family Hygrophoraceae}

Berdasarkan pengamatan dilapangan, ditemukan satu jenis jamur yang termasuk dalam famili Hygrophoraceae. Jamur ini merupakan salah satu jenis jamur liar yang mempunyai bentuk dan sifat tumbuh sama seperti hidnum. Morfologi jamur ini juga cantik karna warnanya yang cerah sehingga enak untuk dilihat dan keindahan dari jamur ini mungkin bisa dijadikan sebagai objek fotografi. Ketika masih muda jamur ini dapat dijadikan obat (Suriawiria, 1993 dalam Saputra, 2015).

- Hygrocybe sp.

Jamur ini mempunyai bentuk tudung berpapila cembung, cembung pada bagian tengah, permukaan tudung halus, tepi tudung bergaris melengkung, bentuk tangkai berukuran sama dari pangkal sampai ujung), tidak ada cincin, tidak ada volva, tepi bilah bergelombang. Tudung berukuran $4 \mathrm{~cm}$. Habitatnya terdapat pada tanah.

\section{Family Hymenochaetaceae}

Tubuh buahnya menghasilkan basidio, yang membedakan mereka dari yang lain adalah tangkai buah dan tudung buah dengan hymenium di bawah bagian belakangnya, atau melekat di belakangnya dan berbentuk melengkung, lebih rata atau lebih seperti susbtrat atau tersusun, dengan hymenium di bagian luarnya (merunduk atau terbalik) dari ukuran kecil hingga ukuran sangat besar 2-2,5 cm, coklat kekuning-kuningan, atau coklat muda, atas coklat kemerahan, coklat tua atau kehitam-hitaman. Tubuh buahnya tumbuh di tanah atau di kayu yang sudah mati dan di kayu yang hidup (biasanya menyebabkan kayu menjadi lapuk dan memutih) (Watson dan Dallwitz, 2012 dalam Saputra, 2015).

- Hymenochaete sp.

Jamur ini mempunyai bentuk tidak beraturan, cembung, pada permukaan berbulu cukup halus. Jamur ini dekomposer kayu mati dan hidup tumpang tindih pada kayu keras. Tudung berukuran $3 \mathrm{~cm}$. Habitatnya berkelompok pada kayu lapuk. 


\section{Family Polyporaceae}

Famili Polyporaceae biasanya disebut dengan polypores karena adanya pori-pori pada himenium dari kebanyakan spesies. Himenium melapisi tabung atau lobang dari dalam . Hifa monomotik, dimitik, ataupun trimitik. Tubuh buah beragam ada yang mirip kerak, papan dan payung, setelah tua umumnya kuat, keras, bergabus dan berkayu. Sebagian besar anggota spesies dari famili ini menyebabkan penyakit pada kayu dan pohon (Darneti, 2006 dalam Saputra, 2015). Jamur Polyporaceae juga berperan sebagai obat diantaranya Microphorus spp., Polyphorus sp., dan Trametes sp. (Noverita dkk, 2017).

- Fomes sp.

Jamur ini mempunyai tubuh buah keras, kaku, berbentuk kipas, tidak bertangkai. Hidupnya Soliter atau berkoloni pada kayu lapuk. Tudung berukuran $7 \mathrm{~cm}$. Jamur ini tidak dikonsumsi.

- Microporus xanthopus

Jamur ini mempunyai tubuh buah lebar, tipis, licin, kaku. Permukaan atas berwarna putih kecoklatan, sedangkan permukaan bawah berwarna putih. Jamur ini memiliki tangkai, tetapi pendek. Tudung berukuran $2,5 \mathrm{~cm}$. Hidup berkoloni pada kayu lapuk. Jamur ini berpotensi sebagai bahan obat.

- Panus sp.

Jamur ini memiliki tubuh buah dalam jumlah yang banyak, berukuran besar, berwarna coklat dengan bentuk seperti corong. Tumbuh berkelompok pada batang kayu yang telah mati.Tidak ada cincin, tidak ada volva. Tudung berukuran $5 \mathrm{~cm}$. Habitatnya terdapat pada kayu lapuk.

- Polyporus sp.

Jamur ini mempunyai tubuh buah keras, liat, dan rapuh apabila kering. Memiliki tangkai sederhana atau pendek. Berbentuk seperti kipas, permukaan licin, berwarna kecoklatan. Tudung berukuran $13 \mathrm{~cm}$. Hidup berkoloni pada kayu lapuk. Jamur ini tidak dikonsumsi.

\section{- Pycnoporus sanguineus}

Jamur ini mempunyai Tubuh buah berbentuk setengah lingkaran, tidak bertangkai, permukaan atas jamur ini licin dan berwarna orange kemerahan, permukaan bawah berpori dan berwarna orange kemerahan terang, tubuh buah keras. Tudung berukuran $6 \mathrm{~cm}$. Jamur ini tidak dapat dikonsumsi. Habitatnya berkelompok pada batang mati. 
- $\quad$ Trametes $s p$.

Trametes memiliki tubuh buah berwarna putih terdapat garis coklat, berbentuk kipas, tekstur seperti kulit, tidak bertangkai, permukaan atasnya licin, permukaan bawahnya (lapisan himenium) berpori, spora berwarna putih. Tudung berukuran $3 \mathrm{~cm}$. Habitatnya pada kayu lapuk, hidup soliter atau berkelompok. Jamur ini tidak dapat dikonsumsi. Jamur berpotensi sebagai bahan baku obat.

\section{Family Schizophyllaceae}

Memiliki badan buah yang terpisah-pisah atau mengumpul, biasanya kecil, penampangnya tak melebihi $3 \mathrm{~cm}$, memiliki bentuk yang berbeda-beda, bentuk ginjal atau kipas, dengan tepi yang rata atau berlekuk, hingga badan buah tampak seperti bercabangcabang. Badan buah berwarna putih, pangkal agak sempit, merupakan bagian yang melekat pada substrat, seringkali memanjang seperti tangkai. Spora silindris, lurus atau sedikit bengkok. Jamur jenis ini bersifat kosmopolitis, banyak ditemukan di daerah tropis, di indonesiapun umumnya terdapat pada kayu-kayu busuk/mati, atau batang-batang yang rebah (Tjitrosoepomo, 1994 dalam Saputra, 2015).

Jamur ini tidak beraroma dan jamur ini merupakan jamur yang paling sering dikonsumsi oleh masyarakat desa Tanjung Kemuning. Jamur ini berpotensi untuk dimakan (Darwis dkk, 2014).

- Schizophyllum commune

Jamur ini memiliki tubuh buah dalam jumlah yang banyak, berukuran sangat kecil, berwarna putih kusam dengan bentuk seperti kipas. Tumbuh berkelompok pada batang kayu yang telah mati.Tidak ada cincin, tidak ada volva. Tudung berukuran 2,5 cm. Habitatnya terdapat pada kayu lapuk.

\section{Family Steccherinaceae}

Steccherinaceae mengandung jamur poroid atau hidnoid. Spora Steccherinaceae biasanya berbentuk silinder atau ellipsoid secara luas. Karakter yang berguna untuk klasifikasi tingkat genus meliputi warna dan jenis tubuh buah, struktur hif yang rinci, adanya sistik, kekuatan reaksi sianofilik hifa atau spora, dan ketebalan dinding spora. Semua spesies menyebabkan busuk putih, dan sebagian besar tumbuh di atas kayu. Sebagian besar spesies 
dianggap memiliki struktur hifa dimitik (mengandung hifa generatif), dan sebagian besar memiliki klem pada septa primer.

- $\quad$ Nigroporus vinosus

Jamur ini memiliki tubuh buah berwarna hitam kusam dengan bentuk seperti kipas. Tumbuh berkelompok pada batang kayu yang telah mati.Tidak ada cincin, tidak ada volva. Tudung berukuran $5,5 \mathrm{~cm}$. Habitatnya terdapat pada kayu lapuk.

\section{Family Tricholomataceae}

Menurut Smith et al., (1979) dalam Khotimah (2015), menyatakan beberapa jenis jamur Tricholomataceae dapat ditemukan pada pohon-pohon, rawa-rawa, tanah di kebun, halaman rumah atau padang rumput. Jamur ini memiliki tubuh mungil, dan bisa dilupakan oleh kolektor. Jamur ini memainkan peran saprobik penting dalam ekosistem hutan, membantu memecah lapisan sampah di lantai hutan. Terdapat pada lapisan serasah, terutama di hutan.

- Marasmius androsaceus

Jamur ini mempunyai tubuh buah kecil, cembung pada bagian tengah sedikit cekung, bergaris-garis atau berkerut. Tangkai seperti rambut kaku berwarna coklat hitam. Habitatnya tersebar pada ranting atau pada serasah daun.

- Marasmius sp.

Jamur Marasmius sp. mempunyai tubuh buah berwarna putih pada bagian tengah kekuningan, mempunyai tangkai. Permukaan licin. Tudung berukuran 3,5 cm.

\section{KESIMPULAN}

Dari pembahasan di atas dapat disimpulkan pada penelitian yang dilakukan di kawasan Taman Wisata Alam Muka Kuning Batam ditemukan 15 jenis jamur tingkat tinggi Basidiomycetes yang termasuk kedalam 7 famili yaitu yaitu Ganodermataceae yang terdiri dari 3 jenis jamur yaitu Amauroderma rugosum, Ganoderma applanatum dan Ganoderma sp. Hygrophoraceae yang terdiri dari 1 jenis jamur yaitu Hygrocybe sp. Hymenochaetaceae yang terdiri dari 1 jenis jamur yaitu Hymenochaete sp. Polyporaceae yang terdiri dari 6 jenis jamur yaitu Fomes sp., Microporus xanthopus, Panus sp., Polyporus sp., Pycnoporus sanguineus 
dan Trametes sp. Schizophyllaceae yang terdiri dari 1 jenis jamur yaitu Schizophyllum commune. Steccherinaceae yang terdiri dari 1 jenis jamur yaitu Nigroporus vinosus. Tricholomataceae yang terdiri dari 2 jenis jamur yaitu Marasmius androsaceus dan Marasmius sp.

\section{REFERENSI}

Badan Pusat Statistik. 2014. Luas Hutan dan Persentase Hutan Menurut Fungsinya 2014. Diakses pada tanggal 22 Maret 2017 di https://batamkota.bps.go.id/ linkTabelStatis/view/id/34.

Campbell, Reece dan Mitchell. 2003. Biologi Jilid 2. Erlangga. Jakarta.

Darwis,W. Desnalianif, dan Rochmah, S. 2014. Inventarisasi Jamur yang Dapat Dikonsumsi dan Beracun yang Terdapat Di Hutan dan sekitar Desa Tanjung Kemuning Kaur Bengkulu. Konservasi Hayati, 7 (2). pp. 1-8. ISSN 0216-9487.

Encylopedia. 2017. Ganodermataceae, artikel diakses tanggal 20 Juli 2017, dari, http://www.encyclopedia.com/science/dictionaries-thesauruses-pictures-and-pressreleases/ganodermataceae.

Hasanuddin, H., 2014. Jenis Jamur Kayu Makroskopis Sebagai Media Pembelajaran Biologi (Studi di TNGL Blangjerango Kabupaten Gayo Lues). Biotik, 2(1), pp.38-52.

Indra, A., 2014. Inventarisasi Jamur Tingkat Tinggi (Basidiomycetes) di Gunung Singgalang Sumatra Barat. (disertasi) Universitas Andalas, Padang.

Khotimah, Siti., I.M Sari dan R. Linda, 2015. Jenis-Jenis Jamur Basidiomycetes di Hutan Bukit Beluan Kecamatan Hulu Gurung Kabupaten Kapuas Hulu. Protobiont . 4(1).

Saputra, A.,2015. Inventarisasi Jamur Makroskopis di Hutan Cagar Alam Durian Luncuk II Batang Hari Kecamatan Batin XXIV Kabupaten Batang Hari.(Skripsi) Universitas Jambi, Jambi.

Sari, K. 2014. Potensi Ekstrak Miselium Ganoderma sp. Isolat Banyumas 1 Terhadap Sel Kanker Payudara (Mcf-7) Pada Lama Inkubasi Yang Berbeda. (Tesis), Universitas Jenderal Soedirman, Purwokwero.

Syafrizal, S. and Yeni, L.F., 2014. Inventarisasi Jamur Makroskopis di Hutan Adat Kantuk dan Implementasinya Dalam Pembuatan Flipbook. Jurnal Pendidikan dan Pembelajaran, 3(9). 
Liska Chairani Harahap, Fauziah Syamsi, Yarsi Efendi: Inventarisasi Jamur Tingkat Tinggi ...

Lampiran 1. Jenis Jamur yang ditemukan pada lokasi penelitian

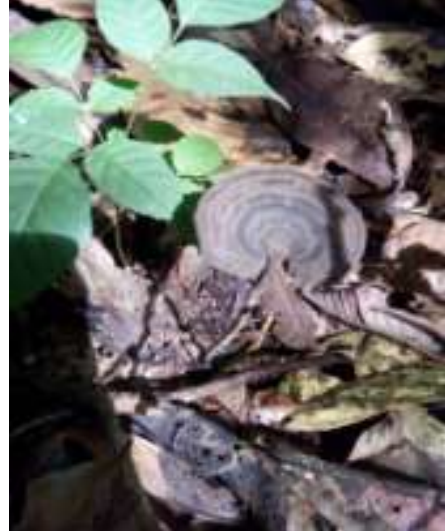

(1). Amauroderma rugosum

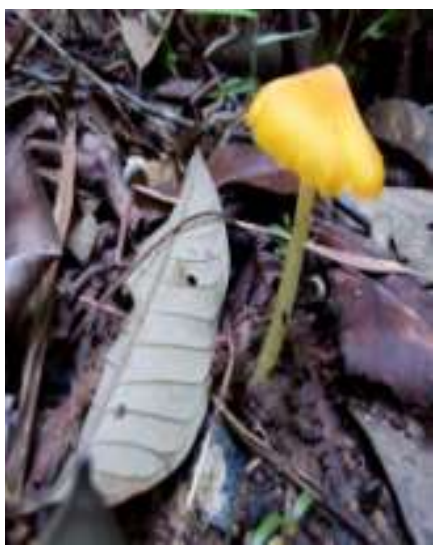

(4). Hygrocybe sp.

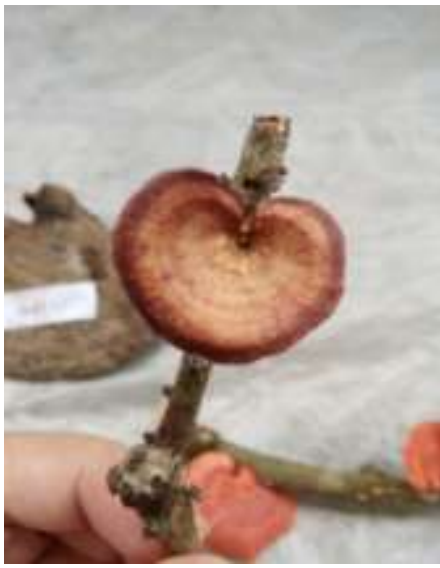

(7). Microporus xanthopus

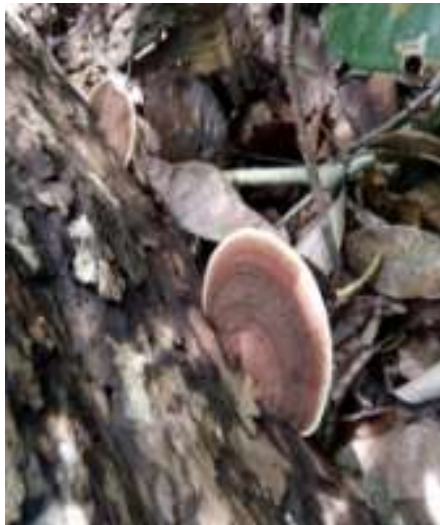

(2). Ganoderma applanatum

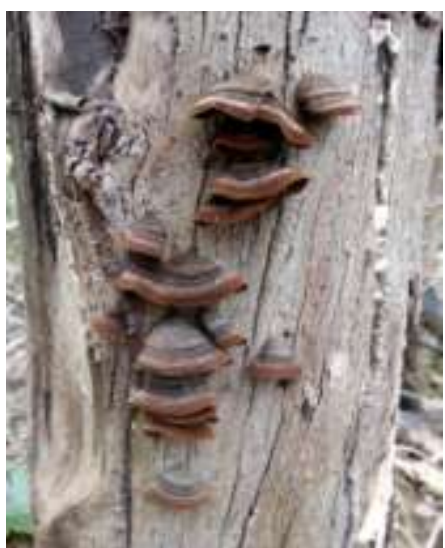

(5). Hymenochaete sp

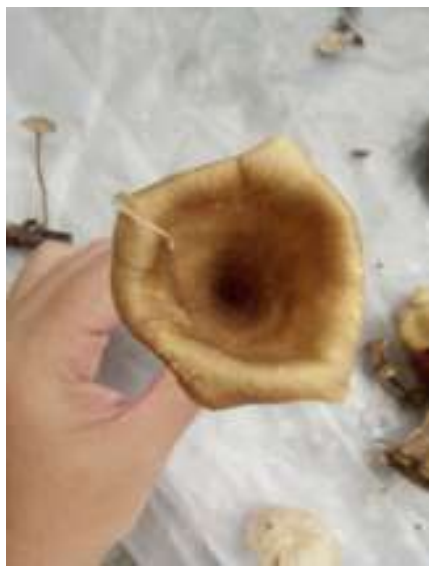

(8). Panus sp.

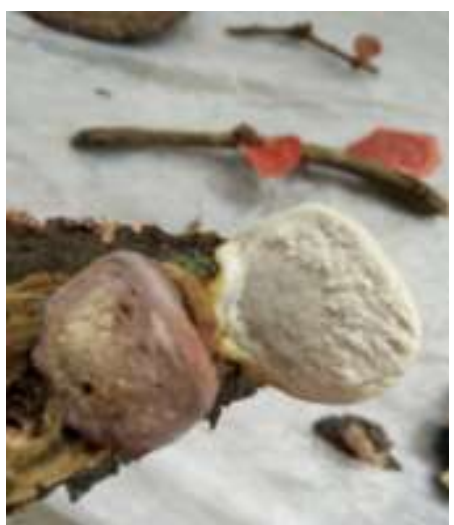

(3). Ganoderma sp

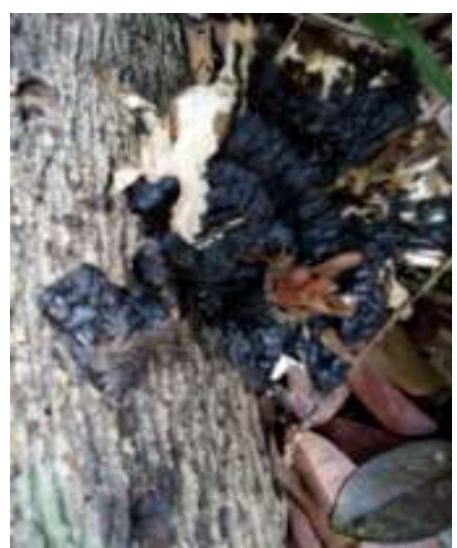

(6). Fomes sp.

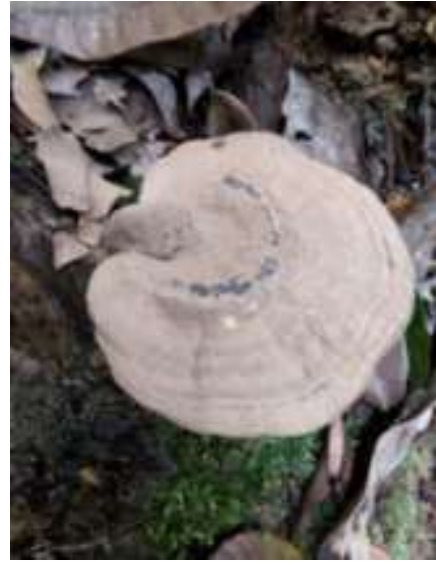

(9). Polyporus sp 


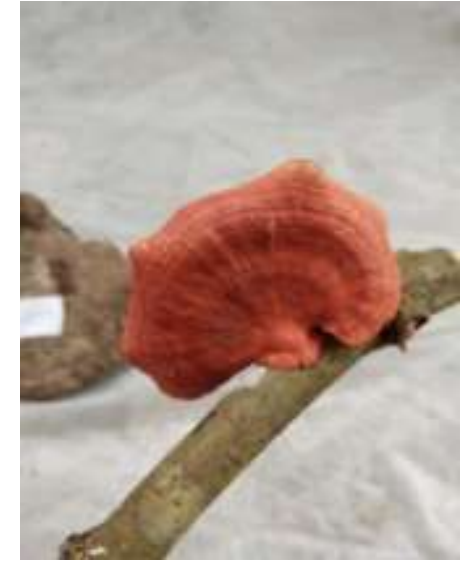

(10). Pycnoporus sanguineus

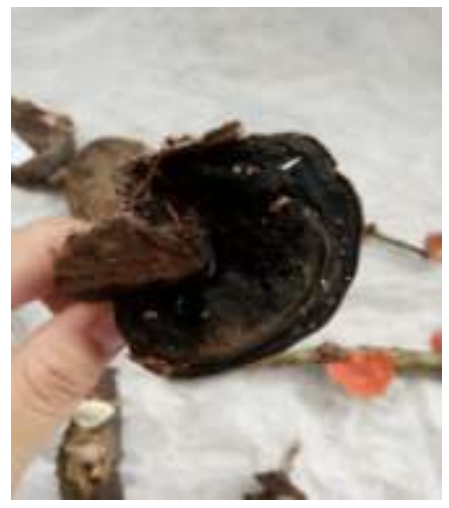

(13). Nigroporus vinosus

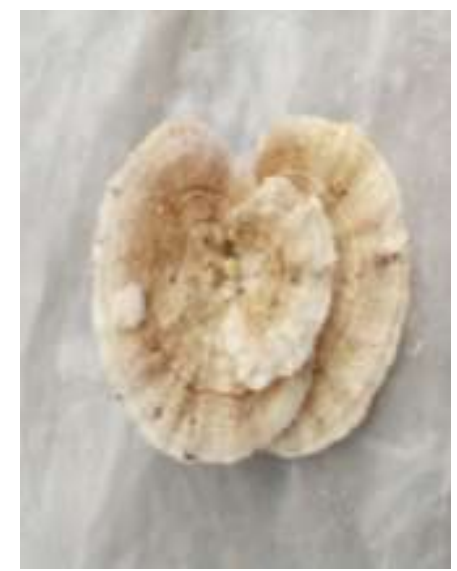

(11). Trametes $s p$.

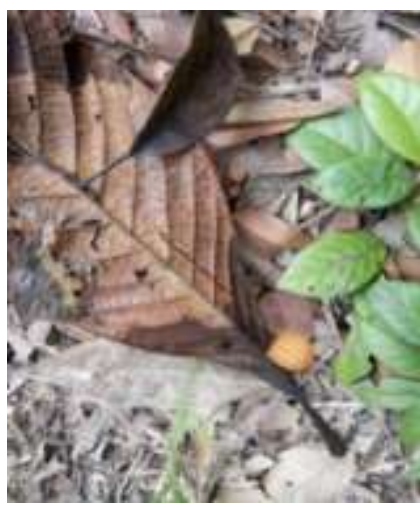

(14). Marasmius androsaceus

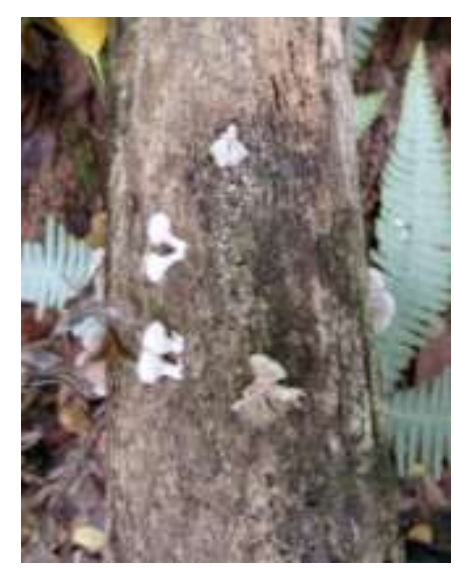

(12). Schizophyllum commune

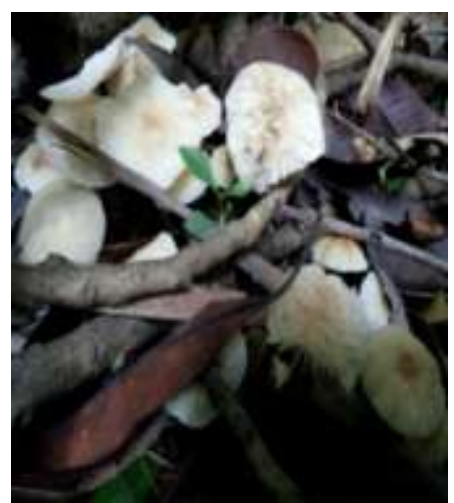

(15).Marasmius sp. 